\title{
The Effect of Action Learning-Based Teaching and Learning Strategies on Metacognitive, Problem Solving, Interpersonal Relationship and Team Efficacy of Nursing Students
}

\author{
Kyung-Hee Chung ${ }^{1}$ and Soon-Gil Park ${ }^{2 *}$ \\ 1506-706 Dept. Nursing, NamBu Univ., 23 Chumdan Jungang-ro, Gwangsan-gu, \\ Gwangju, Korea \\ 2*506-706 Dept. Elementary special education, NamBu Univ., 23 Chumdan \\ Jungang-ro, Gwangsan-gu, Gwangju, Korea \\ psoongil@nambu.ac.kr
}

\begin{abstract}
The study is a single-group experiment design for the operation and measurement of nursing management practice training by applying action learning-based teachinglearning design. The study performed a total convenience sampling of 105 senior nusing students of $N$ University in $G$ Metropolitan City who applied for nursing management practice curriculum. The nursing management practice was implemented from Aug. 4 to Sept. 26, 2014. Each team consists of 4-8 subjects who participated in the practice for two weeks, for a total eight weeks. Prior to practice, pre-survey was carried out and postsurvey upon the completion of the practice. A skill survey tool of metacognitive tools developed by Printrich \& Groot(MSLQ) edited by Woo, and Marshall(2003), and modified by Kwon (2010) was used as a a tool to measure initiative in problem solving, understanding of interpersonal relationships, and team efficacy. The study result showed a statistically significant difference in subjects in Metacognitive $(t=-5.124, p<.001)$, initiative of problem solving $(t=-5.817, .000)$, understanding of interpersonal relationships $(t=-4.947, .000)$, and team efficacy $(t=-3.483$, .001) after participating in action learning-based team project activities.
\end{abstract}

Keywords: Action learning, metacognition, problem solving, interpersonal relationship, team efficacy

\section{Introduction}

\subsection{Need for Research}

The primary goal of nursing education is to cultivate excellent nursing manpower [1], and with the expansion of the role of nurses and the diversification of their works, it became necessary to recruit nurses with flexible thinking, cooperative attitude, creativity and initiative in problem solving capability.

With this in mind, the importance of practical training that provides learning experience to nursing students for practical use of theoretical knowledge is on the rise.

Clinical practice of nursing universities is a core process for recreating nursing skills acquired in theory courses to knowledge that can be unified and applied in clinical use. In this regard, the Korean Accreditation Board of Nursing Education suggested [2] core competency and learn-ability of nurses and each university to strive to develop the curriculum that reflects philosophy and characteristics of nursing education and learnability and assessment systems. As various teaching-learning methods effective for learnability achievement are introduced in theoretical as well as practical training, the need to

${ }^{*}$ Corresponding Author 
use action learning teaching-learning methods has also increased to cultivate problem solving and interpersonal capability through teamwork.

Action learning ensures that students learn cooperation through team activities and achieve curriculum goals based on learner-centered education, and to promote enhancement of class satisfaction [3]. In clinical practice, learners should be able to find and solve the various problems of nursing practice related to nursing clients, works, and environment; it is important that subjects must be very aggressive. Learners are able to find on-site problems through action learning-based team projects and are able to come up with solutions through creative and innovative approach methods to problems by implementing actual projects. Therefore, the purpose of the study is to apply action learning teaching-learning strategies in clinical practice for the development of the practical competency of nursing students, to grasp the effectiveness of capacity development, and to metacognitive, understanding of interpersonal relationship, initiative of problem solving, and team efficacy according to team projects for task process improvement and performance creation in actual site.

\subsection{Purpose of Research}

This research aimed to design and run the class by adopting the team-based action learning teaching-learning methods in 'nursing management practice' curriculum and identify the effect of the curriculum on the capacity building of nursing students in leadership, cooperation, and coordination by analyzing the introspective note, metacognition, activeness of problem solving, understanding of personal relationship, and team efficacy.

\subsection{Definition of the Terms}

\subsubsection{Team-Based Action Learning Teaching and Learning Methods:}

Action learning is a process where students form study teams and address their individual or team projects with their learning coach and at the same time learn the content of project and problem solving process by obtaining knowledge, raising questions, exchanging feedback and introspecting [4]. In this research, action learning is a learning process under the team-based action learning teaching and learning design, developed by the researcher in cooperation with the supervisor for 2 weeks after the study teams select the project in Nursing Management Practice curriculum ( 2 credits), which opened the second semester of 2014, for $1054^{\text {th }}$ year nursing students.

\subsubsection{Activeness of Problem Solving:}

The activeness of problem solving refers to the level of activeness to address the issue by proactively collecting data and taking proper actions in the situation after expecting the issues that may occur regarding the team activities [5].

\subsubsection{Understanding of Interpersonal Relationship:}

Understanding of interpersonal relationship is the level of mutual understanding between the team members, in which the team members talk about each other's preference, strength, and weakness or know such factors without a word. [5].

\subsubsection{Team Efficacy:}

Team efficacy is the shared trust of the group about a common ability to organize and implement a series of behaviors required for accomplishing the project at a given level [6]. 


\section{Research Content}

\subsection{Curriculum Design of Action Learning-Based Nursing Management Practice}

The purpose of nursing management practice curriculum is to connect the theoretical knowledge and grounds of nursing management through practical trainings on the nursing management practice of hospitals and nursing organizations using the knowledge obtained from the theoretical activity of nursing management, and develop analysis and assessment capacity, acquire the job performance ability using the understanding of the nursing standard and standard of professional nurse and creative problem solving ability, as well as management leadership for cooperation and coordination.

The team-based action learning teaching-learning method needs training and methods to address the issues in a creative manner, using several factors of creativity in order to real problems in the field of nursing practice. This curriculum is a process to come up with the problem solving solutions on practical issues led by the team, consisting of a proper number of students through various interactions after discovering the subject of interest in practice that needs to be addressed, and at the same time to learn the project content and problem solving perspective by obtaining knowledge, raising questions, exchanging feedbacks, and introspection during the process.

This curriculum designed and applied the team-based action learning teaching and learning methods using the 4-step action learning-based problem solving process.

As to the team-based action learning teaching and learning methods, it is necessary to form the team for carrying out the projects; identify the issues to be addressed in the first step; analyze the cause of the problem in the second step; develop solutions to the issue in the third step; apply the action plan in the fourth step; and follow up on it.

\subsection{Action Learning-Based Nursing Management Practice Training}

The purpose of problem solving project based on action learning in training of nursing management practice is to develop comprehensive action learning-based problem solving capability by using and acquiring practical experiences and techniques by creative problem solving process steps to improve nursing works/service in the clinical setting and develop new tasks. Action learning team study was carried out in three steps of preparation, operation and evaluation (Table 1).

\subsubsection{Preparation Step}

In the preparation step, the practice plan including learning objectives of the curriculum, curriculum operation and evaluation plan was developed, and the orientation on curriculum was conducted about the plan for nursing management practice, procedure and method of action learning team project on Friday in the week right before starting the practice.

As to forming the study team, a total of 16 teams were created with 4-8 members per team by combining 1-3 units of practice based on the practice planning schedule, and the team leader and clerk were selected per team. Each team was asked to set the team name, team slogan, team motto and ground rule on the first day of practice and start the team study by shouting the team slogan at the beginning and ending of every team meeting.

The guideline for team learning encouraged the entire team members to participate in the study team meeting, to play the role as commentator and clerk in turn in every team meeting, to accomplish the goal of the team meeting by preparing agenda in advance for study team meeting and have time for introspection 10 minutes before the end of the team meeting. 


\subsubsection{Operation Step}

The operation step consists of 4 stages and was carried out for a total of 2 weeks.

\section{Stage 1: Identification of Problems}

This step includes project selection, environmental analysis and identification of structure of problems to identify the suitable problems to action learning in the field of nursing. In addition, as the first stage of action learning, the project statement was written to draw the blueprint that would suggest the ultimate direction. The project statement is a one-page document that accurately describes the background of project selection and the specific results a team needs to achieve or the ideal figure to ultimately accomplish when the project is conducted.

(1) Project Selection: The issues that a team needs to be practically addressed will be preferentially selected among the problems in the field of nursing that are discovered without any prejudice. The proper issues for action learning provide teams and team members with the opportunity to act and learn. Among various issues, the decision grid for optimal project selection is a tool to help select proper projects according to the achievement results and goals of the participants.

(2) Environmental Analysis: To objectively and deeply identify the issues discovered in the field of nursing and nursing unit, the internal and external environments need to be analyzed through cooperative communications among nurses, other medical practitioners, and patients. The research may review relevant regulations or guidelines to identify accurate and objective facts, or analyze the questionnaire and interview techniques to figure out the field.

(3) Identification of Problem Structure: The research breaks down the issues derived from project selection and environmental analysis into small issues to handle. What tree using the MECE (Mutually Exclusive Collectively Exhaustive) technique that is not overlapped, mutually exclusive and the total becomes the whole value for segmentation is a useful technique to come up with the fundamental problems.

\section{Stage 2: Cause Analysis}

The cause analysis stage is to develop and verify the hypothesis on the discovered issues and identify the fundamental causes. This includes selecting key issues, establishing analysis plan, data collection and analysis, and coming up with the fundamental causes.

(1) Selecting key issues and establishing an analysis plan:

The issues discovered in the field do not appear in objective numbers. Therefore, it is possible to reduce the trial and error and specifically assume the type of issues by setting the hypothesis and establishing the analysis plan.

(2) Data collection and analysis: Various data collection methods were used to prove the hypothesis. They include questionnaire, field research, interview and literature investigation. As each method has a strength and weakness, using various methods will improve the quality of collected data rather than using a single method. When the analysis results using various data collection methods to identify one issue are same or similar, more valid verification is possible.

(3) Coming up with the fundamental causes: It is the process to identify the key causes of the discovered issues and materialize in depth the issues through the causal process of thinking of 'why' using the why tree. 


\section{Stage 3: Solution Development}

(1) Coming up with the solutions: This is a process to produce feasible creative ideas to prepare solutions based on the understanding of the cause of the issues. It produces the optimal solutions with positive impacts in the field of nursing using idea releasing methods including brainstorming and lotus blossom.

(2) Evaluation and Selection: Once the fundamental causes are found, it is necessary to search for more specific solutions using the how tree to address the issue. Given the priority and feasibility of each solution, the measures to address the issue will be decided during the process.

\section{Stage 4: Implementation of Solutions and Follow-up}

(1) Action Plan Establishment: Once the final solution is determined, it is possible to reduce the trials and errors only after establishing the plan before implementing the solution. It will be better to build the action plan in a specific, measurable, achievable and outcome-oriented manner within a limited time frame.

(2) Implementation and Follow-up: The implemented solutions will be evaluated and complemented through the feedbacks considering whether they brought about desirable changes, whether the issues reoccur, what kind of impacts the solutions have, and whether they were ethical.

\subsubsection{Evaluation Step}

This was the step to finalize the nursing management practice training, and was conducted on Saturday after practice. The results of the team projects were announced and evaluated, after which feedbacks were given.

\section{Method}

\subsection{Research Design}

The study is a single-group experiment design that designed, operated, and measured nursing management practice training by applying action learning teaching-learning methods.

\subsection{Subjects}

The study performed a total convenience sampling of 105 senior nursing students of $\mathrm{N}$ University in G Metropolitan City who applied for nursing management practice curriculum. The subjects are students who understood and consigned the purpose of the study.

\subsection{Data Collection}

The nursing management practice was implemented from Aug. 4 to Sept. 26, 2014. Pre-survey was carried out prior to practice and post-survey upon the completion of the practice.

\subsection{Research Tools}

The metacognitive tools developed by [7] (MSLQ;Motivated Strategies for Learning Questionnaire) that was edited by [8]. Cronbach' $\alpha$ value is .95 in the current study.

The adaptability measuring tool, one of the five subdomains of team skill survey of [9], which was edited by [10], was used for measuring initiative in problem solving. The tool has a total of 8 items and the higher the point of 5-point Likert scale is, the more the initiative in problem solving inheres. Cronbach' $\alpha$ value of creditability at the time of 
development was .86, and .827 in Kwon's study [10], and .91 in the current study.

The measuring tool for the understanding of interpersonal relationships, one of the five subdomains of team skill survey of [9], used the one edited by [10]. The tool has a total of 11 items, and the higher the point of 5-point Likert scale is, the more the understanding of the interpersonal relationships inheres. Cronbach' $\alpha$ value of creditability at the time of development was .86, and .859 in Kwon's study [10], and .95 in the current study.

The team efficacy scale of [9] that was edited by [10] was used for team efficacy measurement. The tool has a total of 8 items, where the higher the point of 5-point Likert scale is, the more the team efficacy inheres. Cronbach' $\alpha$ value of creditability at the time of development was 0.89 , and .966 in Kwon's study [10], and .94 in the current study. The researcher developed 5 introspection question items for self-examination.

\subsection{Research Process}

The researcher designed teaching-learning methods by reflecting knowledge acquiring, questions and reflection, commitment, and learning-coach roles for tasks, learning teams, task details and problem-solving process, which are the six core elements of action learning to nursing management practice training based on years of action learning experience. Action learning-based nursing management practice was conducted from August 4 to September 26, 2014 for eight weeks and two weeks for each learning team.

The total of 16 teams, with each team consisting of 4-8 subjects, participated in clinical training for two weeks. The learning team selected tasks for practice process improvement and performance creation of nursing practice, and carried out team tasks by applying action learning-based team project activities and problem solving process.

The learning coach implemented coaching a total of four sessions for two weeks, one to two hours per session, twice a week as collaborative partnerships between instructorlearner, and also supported learning teams by problem solving step, such as e-mail, feedback over the phone, visiting.

Guidelines and various forms for progress and results of projects were provided and appropriate tools according to problem solving steps were instructed. Team members designed an agenda and implemented task solving activities through team learning once a day, one to two hours, and ensured to conduct team reflection after team activities and wrote a daily $\log$ for comprehensive individual reflection upon the completion of practice. In advance to practice, orientation was performed for action learning-based problem solving project implementation.

\subsection{Data Analysis}

The study analyzed collected data by using the SPSS WIN 20.0 Program. Descriptive statistics was performed for the general characteristics of the subjects, and Cronbach' $\alpha$ was calculated for the creditability of assessment tools. Paired t-test was used to analyze metacognitive, initiative in problem solving, understanding of interpersonal relationships, and a difference of team efficacy before/after action learning-based team project activities.

The introspection journal was the underlined, analyzed and summarized key content by the researcher as the content was thought to be meaningful.

\section{Research Findings}

\subsection{General Characteristics of subjects}

Of the 105 study subjects, female students occupied the most, accounting for $91.4 \%$ (96 students), while male students accounted for $8.6 \%$ ( 9 students). The average age of the subjects was 22.6 (21-34 years of age). 


\subsection{The Difference of Dependent Variable After Action Learning-based Team Project Activities}

Metacognitive ( $\mathrm{t}=-5.124, \mathrm{p}<.001)$, Initiative of problem solving $(\mathrm{t}=-5.817, \mathrm{p}<.001)$, understanding of interpersonal relationships $(\mathrm{t}=-4.947, \mathrm{p}<.001)$, team efficacy $(\mathrm{t}=-3.483$, $\mathrm{p}=.001)$ of subjects showed a statistically significant difference after activities of action learning-based team projects (Table 1).

\section{Table 1. The Difference of Dependent Variable after Action Learning-based Team Project Activities}

\begin{tabular}{lcccc}
\hline \multirow{2}{*}{ Variables } & \multicolumn{2}{c}{$\mathrm{M} \pm \mathrm{SD}$} & \multirow{2}{*}{$\mathrm{t}$} & $p$ \\
\cline { 2 - 3 } & Pretest & Posttest & & \\
\hline Metacognitive & $3.74 \pm 0.53$ & $4.02 \pm 0.54$ & -5.124 & .000 \\
Initiative of problem solving & $3.98 \pm 0.52$ & $4.30 \pm 0.51$ & -5.817 & .000 \\
Understanding of interpersonal & $4.23 \pm 0.51$ & $4.52 \pm 0.45$ & -4.947 & .000 \\
Relationship & $4.18 \pm 0.56$ & $4.42 \pm 0.56$ & -3.483 & .001 \\
Team efficacy & & & & \\
\hline
\end{tabular}

\subsection{Analysis of Introspection}

The analysis results of personal introspection after the action learning-based problem solving team activities are listed in Table 2.

\section{Table 2. Personal Introspection after Action Learning Team Activities}

\begin{tabular}{|c|c|}
\hline Question & Introspection \\
\hline $\begin{array}{l}\text { 1. Among the learning } \\
\text { content as a team after the } \\
\text { action learning-based } \\
\text { team activities, what is } \\
\text { the most important } \\
\text { lesson? }\end{array}$ & $\begin{array}{l}\text { Making the most of the strong points and receiving assistance from other team } \\
\text { members on the weak points; importance of mutual consideration and respect } \\
\text { between team members, importance of cooperation and communication, mutual } \\
\text { encouragement between team members; sincere fulfillment of each } \\
\text { responsibility, coming up with the solutions given the feasibility and practicality } \\
\text { and carrying the ideas into practice. }\end{array}$ \\
\hline $\begin{array}{l}\text { 2. What kind of } \\
\text { knowledge did you } \\
\text { obtained from the team } \\
\text { activities? }\end{array}$ & $\begin{array}{l}\text { Action learning problem solving process, perspective to discover the points and } \\
\text { strength of the hospital ward practice, search and summary of research papers } \\
\text { related to the project, how to find the causes of the issue, What-Why-How tree, } \\
\text { decision making method and alternative assessment method. }\end{array}$ \\
\hline 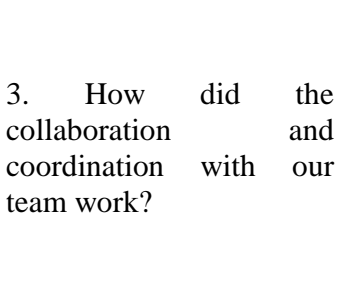 & $\begin{array}{l}\text { Based on a thorough role assignment, the works were completed with } \\
\text { responsibility. Our team helped other team members understand our opinions } \\
\text { with reasonable explanations. We did not argue my own opinions only but } \\
\text { respected and encouraged each other to show the best teamwork. We completed } \\
\text { the project by complying with the team ground rule. All members participated in } \\
\text { meetings, presented opinions, and encouraged and helped each other so that the } \\
\text { activities went well. During the process of combining various opinions, the } \\
\text { quality of thoughts improved. }\end{array}$ \\
\hline $\begin{array}{l}\text { 4. During the team } \\
\text { activities, which factors } \\
\text { affected the emotions, } \\
\text { opinions and response of } \\
\text { me and my team? }\end{array}$ & $\begin{array}{l}\text { Cooperation, communication, respecting and reflecting each other's opinions, } \\
\text { activeness and consideration, not depending on the team leader and playing each } \\
\text { role, sympathy and listening, mutual complimenting between team members, } \\
\text { creative idea releasing activities through team discussion, You may go fast alone } \\
\text { but go further together, sharing each member's idea within the team. }\end{array}$ \\
\hline $\begin{array}{l}\text { 5. What kind of help do } \\
\text { you think the learning } \\
\text { content from the action } \\
\text { learning team activity } \\
\text { will give in your future } \\
\text { works? }\end{array}$ & $\begin{array}{l}\text { We will apply the experience of search the solutions from various perspectives } \\
\text { on the issue, using the data collection method, cooperation activities in the team } \\
\text { project to team nursing. Critical thoughts, how to deduct creative ideas, decision } \\
\text { making method through discussion, search the subject-centered solution in QI } \\
\text { activities, role assignment method }\end{array}$ \\
\hline
\end{tabular}




\section{Discussion}

The eight abilities expected from students in nursing education are basic skills, ability to think, problem solving skills, interpersonal skills, professional skills, information literacy, global capabilities, and voluntary spirit [11]. Of the abilities expected from students in nursing education, effective communication ability and interpersonal relationships are suggested as the most important qualities required for professional nurses in the department of nursing graduates [12, 13]. Therefore, programs that can develop such capabilities should be included in curriculums. The study recognized communication and interpersonal relationship abilities very importantly in hospital practice environment where various professionals work together in terms of work efficiency promotion. The study applied action learning-based team project teachinglearning strategies and confirmed effect for problem solving capability development required for nursing team members who need to implement nursing practice in the face of problem solving related to hospital environment, administrative systems, and subject. The researcher, as a profession of nursing management practice training, finds actual problems in nursing practice of details of planning, organization, personnel, command and control area, which were learned in theoretical curriculum, and applied to the problem solving process, and design and operate action learning-based teaching-learning strategies that help learning problems and problem solving process. Action learning is a process where learners organize teams to learn the detail aspects of tasks and aspects of task implementation process together with a learning coach based on tasks [14]. The study confirmed a significant increase in subjects of metacognitive, initiative in problem solving, understanding of interpersonal relationships, and team efficacy capability after participating in action learning-based team project activities.

Metacognition is an activity to take advantage of the knowledge and strategy and controlling. The subjects of this study were improved in the level of metacognition as a team project activities. In addition, Action learning team projects reflect the individual cognitive processes, results, and help to leverage the knowledge of the individuals involved in it.

In the case of initiative in problem solving, the result is similar to that of the study [15] that had shown a significant increase in problem solving process after applying the action program to nursing management practice or the study [16] that had shown an increase by 3.55 points from 3.20 points in problem-solving skills of nurses after applying the action program. Problem solving ability of all subjects of all of these studies showed improvement after educational interventions, and it was confirmed that problem solving capability could be improved by educational interventions even if the initial level is different.

The understanding of interpersonal relationships means team members are aware of mutual preference, concern, and strength and that would lead to effective knowledge sharing and opened communication within a team [17]. That is, the level of understanding of interpersonal relationships can be an important requirement for action learning performance. According to research results [18] that knowledge related to team members has a high correlation associated with team task implementation [19], and that the more the knowledge about team members is recognized, the higher the team performance in terms of team activities indicates, and that the key factor for task success in action learning programs is the level of team building [14], the level of the understanding of interpersonal skills in the study show a significant difference before/after project activities, where the study confirmed very active communication and interaction between teams during action learning project implementation and that such activities had positive effects on task solving [20].

Team efficacy of subjects has increased significantly before/after project team activity participation, which is the similar result observed in the study that confirmed increase of 
team efficacy after web-based situated learning [21]. The finding supports the study result [22] in which the occurrence of interaction between team members affect team efficacy of team members; it appears the result of the study, therefore, is due to active mutual learning in team project meeting process for two weeks, two hours each day. However, the instructor believes that facilitation provided by participating in team meeting (a total of eight hours, two times a week, two hours per session) also helped improve team efficacy based on the reflection of [12] according to students who completed the education engineering subject in accordance with action learning design - "it was extremely difficult to adjust opinions between team members and that it required too much time", and literature review that an instructor is required to identify requirements of students and provide necessity in time to ensure implementation of the characteristic of action learning that supports learning through reflection of a problem solving process while solving actual problems until the period specified based on team work.

The study is an effective teaching-learning strategy in that it confirmed positive results, which satisfy the characteristics of nursing science, which is practice-oriented applied science by applying an action learning method through subjects active participation in practical problem solving through effective interpersonal ability and teamwork in a medical environment where members of various professional work together.

\section{Conclusion}

The study was able to confirm that action learning-based team project teachinglearning methods are effective for improving metacognitive, initiative in problem solving, understanding of interpersonal relationships, and team efficacy. Furthermore, additional study is required related to effectiveness of action learning-based team project learning with regard to majoring theories of nursing science and practical course, including nursing management practice, and analysis of the level of the improvement of the dependent variable through comparative study among problem-based learning, simulation learning, and other team-based learning methods.

\section{Acknowledgments}

This work was supported by the National Research Foundation of Korea Grant funded by the Korean Government (NRF-2013S1A3A2054928).

\section{References}

[1] J. Greenwood, "Critique of the graduate nurse: An international perspective", Nurse Education Today, vol. 20, (2000), pp. 17-23.

[2] Korean Accreditation Board of Nursing Education, http://www.kabon.or.

[3] S. H. Jang, "Search on morality that Korean society requires: Focused on the case of teaching-learning in elementary moral education applying action learning", Elementary Moral Education, vol. 36, (2011), pp. 111-142.

[4] H. C. Bong, "Action Learning Workbook, Dasan", Seoul, (2005).

[5] V. U. Druskat and D. C. Kayes, "Learning and Performance in short-term project teams", Small Group Research, vol. 31, no. 3, (2000), pp. 328-353.

[6] A. Bandura, "Self-efficacy: The exercise of control", Freeman, (1997).

[7] P. R. Printrich and E. Groot, "Motivational and self-regulated learning components of cognitive processing during instruction", Journal of Educ Psychol., vol. 82, (1990), pp. 33-40.

[8] O. H. Woo, "The effects of problem based learning on the problem solving process of students by their metacognitive levels", unpublished master's thesis, Korea National University of Education, ChungBuk, Korea, (2000).

[9] L. C. Marshall, "The relationship between efficacy, teamwork, effort and patient satisfaction", Doctoral dissertation, the university of southern California, (2003).

[10] E. M. Kwon, "The correlation among team efficacy, interpersonal understanding, proactivity in problem solving and team performance", unpublished master's thesis, Ewha Womans University, Seoul, Korea, (2010). 
[11] J. H. Park, "Study of abilities required to develop for student in nursing education", Journal of Korean Acad Nurs Admin, vol. 17, no. 1, (2011), pp. 74-87.

[12] C. J. Kim and Y. H. Ahn. M. W. Kim. Y. O. Jeong. J. Lee, "Development of standards and criteria for accreditation of a baccalaureate nursing education program: reflections on the unique characteristics of the nursing profession", Journal of Korean Acad Nursing, vol. 36, no. 56, (2006), pp. 1002-1011.

[13] I. H. Freeman and R. R. Voignier. D. L. Scott, "New curriculum for a new century: beyond repacking", Journal Nursing Education, vol. 14, no. 1, (2002), pp. 38-40.

[14] H. C. Bong, "Do action learning for success", Hangseong B wave, (2012).

[15] Y. M. Kim and Y. H. Kim, "Development and education of action learning in clinical practice of nursing management", Journal of Korean Contents Association, vol. 10, no. 6, (2010), pp. 312-322.

[16] S. J. Lee, "The effects of action learning program on nurse's problem solving and communication skills. unpublished doctoral dissertation", Chonnam National University, Gwangju, Korea, (2009).

[17] Y. M. Lee, "The effects of shared mental model on learners and team performance in web-based team learning environment", Journal of Korean Society for Educational Technology, vol. 21, no. 3, (2005), pp. 77-96.

[18] J. E. Mathieu and T. S. Heffner. G. F. Goodwin. E. Salas. J. A. Cannon-Bowers, "The influence of shared mental models on team process and performance", Journal if Applied Psychology, vol. 85, no. 2, (2000), pp. 273-283.

[19] Y. M. Lee and T. J. Kim. J. I. Kim. S. P. Jang. J. Y. Hong, "The effects of task performance and group efficacy in web-based situational learning environment", Journal of Educational Studies, vol. 37, no. 3, (2006), pp. 47-75.

[20] K. H. Chung and S. G. Park, "The Effect of Action Learning-based Teaching and Learning Strategies on Competency Development of Nursing Students", Proceeding of the 7th International Workshop of ASTL and Healthcare and Nursing V, (2015); Jeju University, Korea.

[21] M. S. Park, "A longitudinal study on the factors affecting team performance among college student: The development of team efficacy perspective", unpublished master's thesis, Hoseo University, Asian, Korea, (2009).

[22] H. L. Roh, "Identifying design factors of action learning in higher education", Journal of Educational Information and Mediam vol. 13, no. 3, (2007), pp. 53-78. 